\title{
Development of a LDIE Prediction Theory in the Condition of Magnetite Formation on Secondary Side Piping in Nuclear Power Plants
}

\author{
Kyeongmo M. Hwang1, Hyeok Kee Seo', Chan Kyu Lee1, Won Chang Nam² \\ ${ }^{1}$ Power Engineering Research Institute, Gimcheon, South Korea \\ ${ }^{2}$ Seoul National University, Seoul, South Korea \\ Email:hkm@kepco-enc.com
}

How to cite this paper: Hwang, K.M., Seo, H.K., Lee, C.K. and Nam, W.C. (2017) Development of a LDIE Prediction Theory in the Condition of Magnetite Formation on Secondary Side Piping in Nuclear Power Plants. World Journal of Nuclear Science and Technology, 7, 1-14.

http://dx.doi.org/10.4236/wjnst.2017.71001

Received: September 22, 2016

Accepted: December 13, 2016

Published: December 16, 2016

Copyright $\odot 2017$ by authors and Scientific Research Publishing Inc. This work is licensed under the Creative Commons Attribution International License (CC BY 4.0).

http://creativecommons.org/licenses/by/4.0/

\begin{abstract}
It has been thought that wall thinning on the secondary side piping in nuclear power plants is mostly caused by Flow-Accelerated Corrosion (FAC). Recently, it has been seen that wall thinning on the secondary side piping carrying two-phase flow is caused by not only FAC but also Liquid Droplet Impingement Erosion (LDIE). Moreover, it turns out that LDIE in nuclear power plants does not result from a single degradation mechanism but also from the simultaneous happenings of LDIE and FAC. This paper presents a comparison of the mass loss rate of the tested materials between carbon steel (A106 B) and low alloy steel (A335 P22) resulting from degradation effect. An experimental facility was set up to develop a prediction model for clarifying multiple degradation mechanisms that occur together. The experimental facility allows examining liquid droplet impingement erosion in the same conditions as the secondary side piping in nuclear power plants by generating the magnetite on the surface of the test materials. The magnetite is formed by controlling the water chemistry and the temperature of fluid inside the facility. In the initial stage of the experiments, the mass loss rate of A106 B was greater than that of A335 P22. However, after a certain period of time, the mass loss rate of A335 P22 became greater than that of A106 B. It is presumed that the results are caused by the different yield strengths of the test materials and the different degrees of buffer action of the magnetite deposited on their surfaces. The layer of magnetite on the surface of A106 is thicker than that of A335 P22, due to the different amount of chrome content. In nuclear power plants, carbon steel piping having experienced wall thinning degradation is generally replaced with low-alloy steel piping. However, the materials of pipes carrying twophase flow should be selected considering their susceptibility to LDIE.
\end{abstract}




\section{Keywords}

Liquid Droplet Impingement (LDI), Flow-Accelerated Corrosion (FAC), Multiple Degradations, Wall Thinning, Magnetite

\section{Introduction}

It has been thought that the wall thinning on the secondary side piping in nuclear power plants is mostly caused by FAC. Recently it has been found that the wall thinning on the secondary side piping carrying two-phase flow is caused by not only FAC but also LDIE. Recently, damage caused by LDIE in South Korea consists of leakage from the vent header connected to the high pressure feed water heater in Wolsong Unit 1 (2008) [1], leakage from the branch line connected to the high pressure turbine in Hanul Unit 2 (2010), and leakage from the end cap connected to the reheater vent line in Hanbit unit 2 (2011) [2]. In all of these cases, magnetite was formed on the surface of the damaged piping, and the surface was pitted with pockmarks.

The theoretical models, which can predict LDIE damages, are the SanchezCaldera model [3] of the Massachusetts Institute of Technology (MIT), and the Heymann model [4] of Westinghouse. In addition, several papers related to LDIE have been published [5] [6] [7]. Magnetite is formed on the surface of carbon steel piping in two-phase flow systems in nuclear power plants. In these systems, steam flows through the center of the pipe and liquid flows in the form of water film along the pipe wall. The liquid on the pipe wall is changed into the droplets when the shear stress is greater than the surface tension at the interface of each phase, and the droplets are accelerated due to the steam flow. When droplets collide with the pipe wall, LDIE damages occur. Therefore, the wall thinning of the piping is affected by multiple degradation mechanisms, i.e., FAC and LDIE. FAC is caused by water flowing on the inside surface of the pipes, while LDIE is caused by liquid droplets colliding with the pipe wall. However, the previous LDIE prediction models did not consider the multiple degradation mechanisms, and also did not consider some key factors among droplet size, impact frequency, impact angle, hardness of the material, etc.

Therefore, in this study, an experimental facility was set up to develop predictive models for the multiple degradations of FAC and LDIE occurring in carbon steel piping. The experimental facility consists of water treatment equipment which can generate magnetite on the materials by adjusting amine concentration, $\mathrm{pH}$, and dissolved oxygen, and a rotating disk-and-droplet repetitive impact apparatus for liquid droplet impingement tests. The test materials were carbon steel (A106 B) and low-alloy steel (A335 P22), which are widely used in the secondary system of nuclear power plants.

\section{Influential Factors to FAC and LDIE}

FAC is associated with mass transfer and dissolution of the magnetite which is 
formed on the surface of carbon steel piping under the operating conditions of high-temperature and high-pressure. On the other hand, LDIE results from the shock wave of high-pressure caused by high-speed collision of droplets to the surface of piping and the spreading water jet with radial shape by droplet disruption.

Figure 1 shows a droplet collision process on the rigid surface which is described in a previous study [8], in which 1) shows the moment when the shock wave initiates immediately after impacting a liquid droplet on the rigid surface, 2 ) is the attached shock front formation step when the contact angle is smaller than the critical contact angle $\left(\phi<\phi_{c}\right)$, and 3) depicts the lateral jet formation step along the rigid surface when the contact angle is larger than the critical contact angle $\left(\phi>\phi_{c}\right)$. At the critical contact angle $\left(\phi_{c}\right)$, the conditions for an attached shock are no longer met; the shock front then detaches from the solid surface and moves up along the surface of the droplet. The solid surface is repeatedly affected by the attached shock, detached shock, and lateral jet. The affected surface can be thinned by falling off of the grain particles, which is damaged by the fatigue-crack at the grain-boundary on the solid surface.

The inside of the carbon steel piping of two-phase flow systems such as the extraction steam system, the main steam system, and the feed water heater vent system of nuclear power plants is operated at saturated steam condition, and therefore the liquid film is formed on the surface of the pipe wall. The liquid flows along the pipe wall by steam flow when the shear stress is smaller than the surface tension at the interface of each phase. On the other hand, the liquid is separated in the form of droplets and accelerated by the steam flow when the shear stress is greater than the surface tension. And then, the droplets collide with the pipe wall. In fact, the droplets hit the water film formed on the surface, not the rigid surface directly. Therefore, the wall thinning of the carbon steel piping under two-phase condition is considered as the multiple degradations caused by FAC and LDIE. Figure 2 shows a typical example of the multiple degradations of FAC and LDIE. The leaked 1 inch pipe was installed in the main steam system of a Korean nuclear power plant. An orifice was installed at the upstream of the pipe and the black magnetite was formed on the surface of the pipe wall. As shown in the figure, the portion of 1) was damaged coarsely by LDIE with FAC, the portion of 2) was damaged only by FAC having the orange peel surface, but the portion of 3) was not damaged.

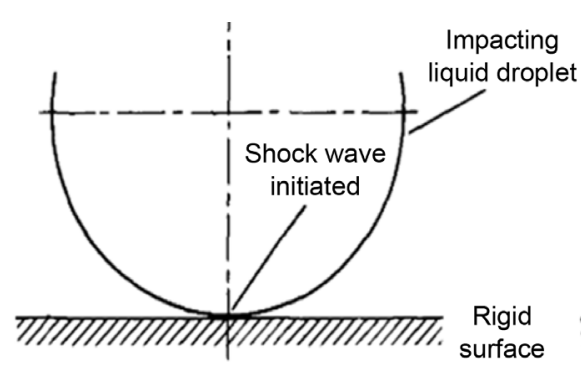

(a)

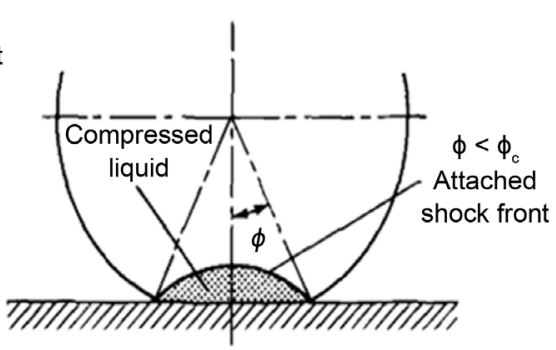

(b)

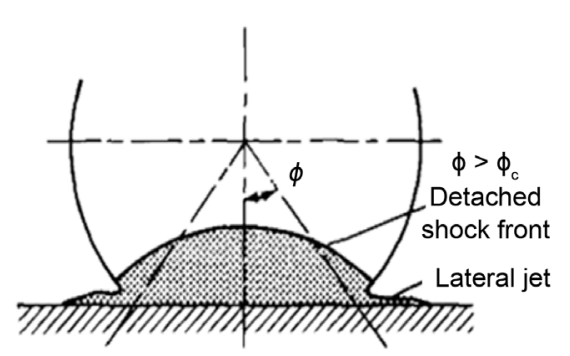

(c)

Figure 1. Liquid droplet collision process on a rigid surface. 


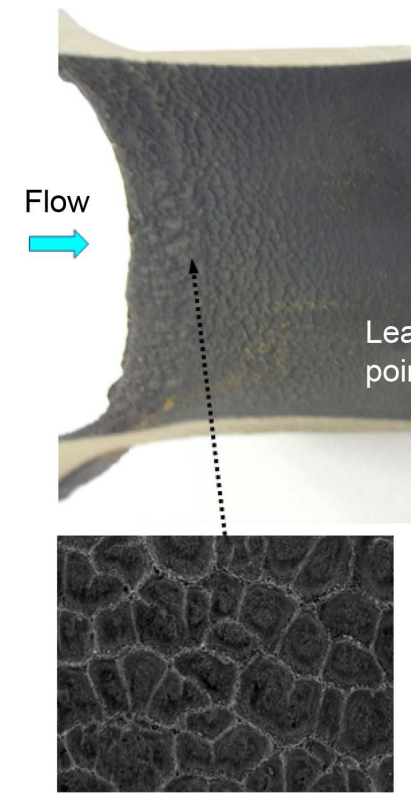

(a)

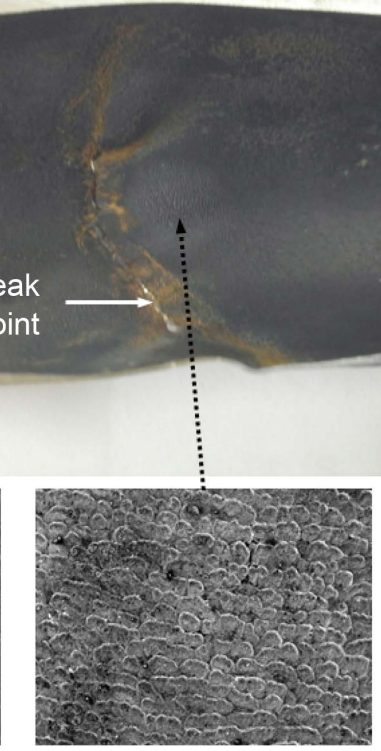

(b)

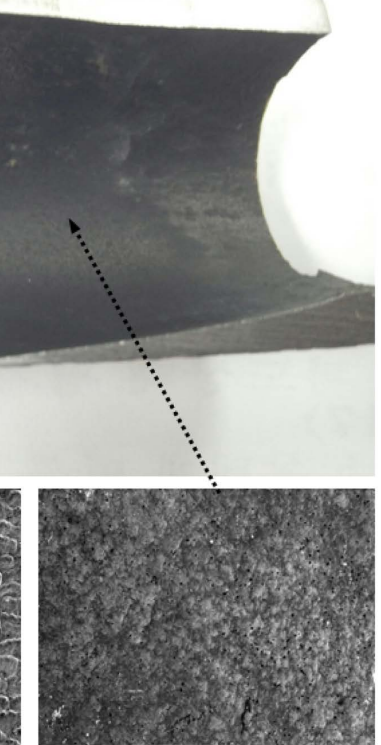

(c)

Figure 2. Typical example of the multiple degradations of FAC and LDIE.

The influential factors of FAC and LDIE are as follows, and the key factors of multiple degradations can be considered as the sum of the following variables:

- LDIE dominant factors: droplet size, droplet velocity, impact frequency, impact pressure, geometry of pipe, steam quality, hardness of material,

- FAC dominant factors: velocity, temperature, $\mathrm{pH}$, alloy content, geometry of pipe, dissolved oxygen, mass transfer coefficient.

\section{Experimental Facility}

To replicate the multiple degradations caused by LDIE and FAC, the experimental facility was designed by applying the rotating disk method presented in ASTM G73-10 [9]. The rotating disk method is that the rotating test specimens are placed at outer circle with the sprayed droplets from a nozzle. And, this method can easily adjust the colliding velocity with the droplets by controlling the velocity of the disk rotation. And it can easily measure the size of droplets using an ultrahigh-speed camera. On the other hand, it takes time to damage the specimen since the collision frequency is relatively low compared to using the water jet method.

Figure 3 shows the schematic diagram of the experimental facility for replication of the multiple degradations. The experimental facility consists of the water treatment equipment and the rotating disk-and-droplet repetitive impact apparatus. The water treatment equipment can generate the magnetite on the surface of the specimens by adjusting temperature, amine concentration, and dissolved oxygen. A nozzle for generating the liquid droplets and eight test pieces for testing several specimens at the same time were equipped in the rotating apparatus. The water chemistry balancing system and the rotating disk-and-droplet repetitive impact apparatus are shown in Figure 4 and Figure 5. 


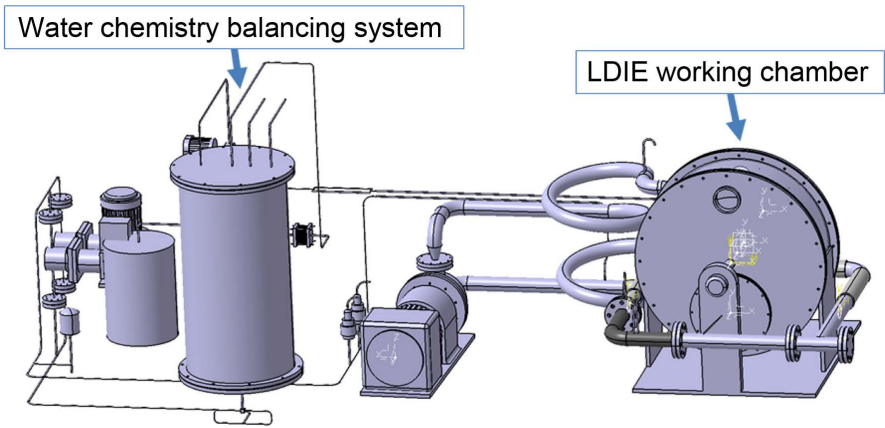

Figure 3. Schematic diagram of the experimental facility.

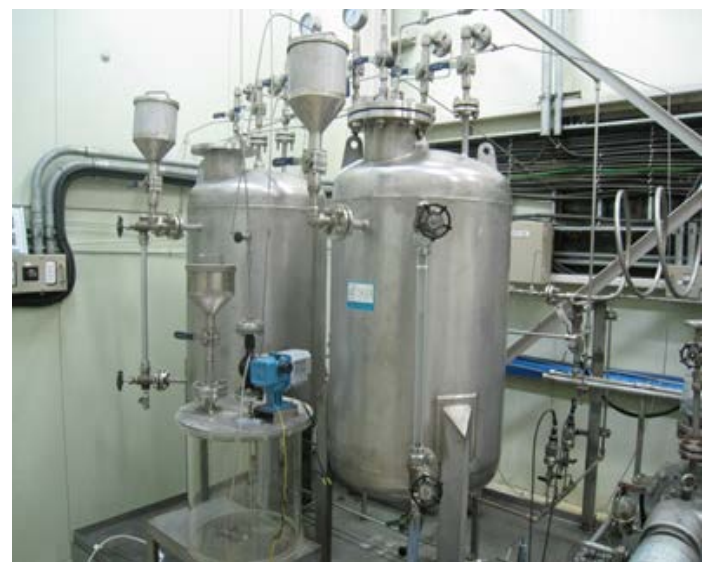

Figure 4. Water chemistry balancing system.

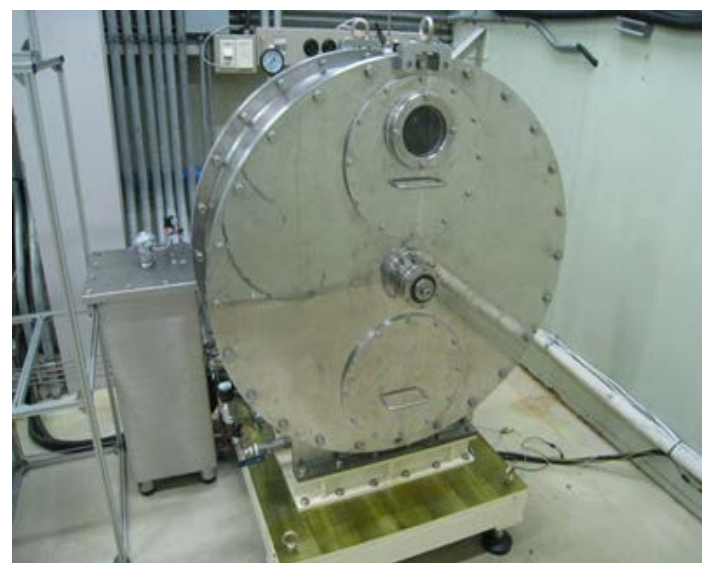

Figure 5. Rotating apparatus.

\section{Experiment Execution and Results}

\subsection{Characterization of the Droplets}

In order to determine the optimal experimental conditions for the droplet size and the Droplet Number Density (DND), which are the key factors to LDIE, the droplet sizes were analyzed using a strobe light source and an ultrahigh-speed camera, and the Stand-Off Distance (SOD), the nozzle size, and the nozzle pressure differences were tested in advance of the tests for the multiple degradations. As the results of the preparatory experiments, the determined nozzle size and 
spray angle were $0.9 \mathrm{~mm}$ and 65 degree, respectively. And, it was identified that the SOD of $80-100 \mathrm{~mm}$ shape in pressure difference of $0.5 \mathrm{~atm}$ was apparently possible to identify the droplet as shown in Figure 6 and Figure 7. As the pressure difference of the nozzle was increased, the droplet size was inversely decreased gradually.

The mean droplets diameter was defined by using the Sauter Mean Diameter (SMD) method. It is defined as the diameter of a sphere that has the same volume/surface area ratio as a particle of interest based on the method of deciphering several images with the naked eye. In the conditions of the nozzle size of $0.9 \mathrm{~mm}$, the pressure difference of $0.5 \mathrm{~atm}$, and the SOD of $100 \mathrm{~mm}$, the DND was 31 per unit area $\left(\mathrm{mm}^{2}\right)$ and the SMD was $655 \mu \mathrm{m}$.

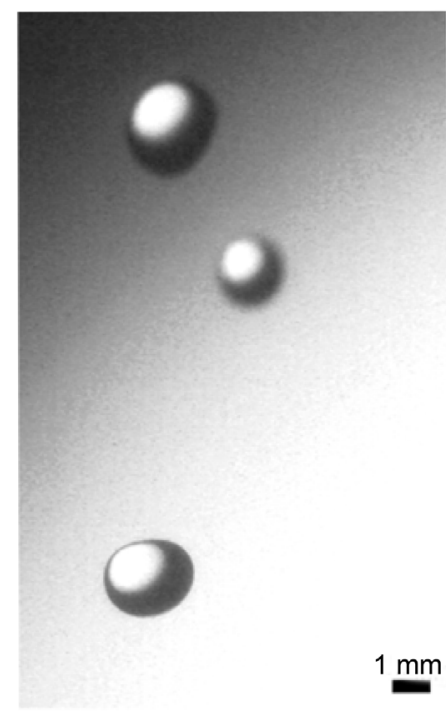

$[\Delta \mathrm{P}=0.5 \mathrm{~atm}]$

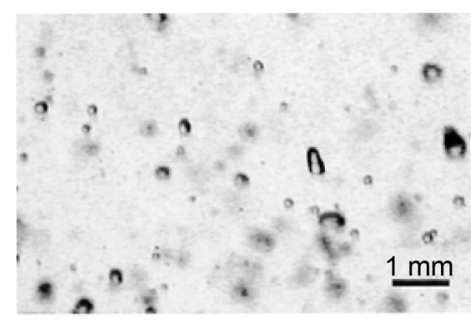

$[\Delta \mathrm{P}=1.0 \mathrm{~atm}]$

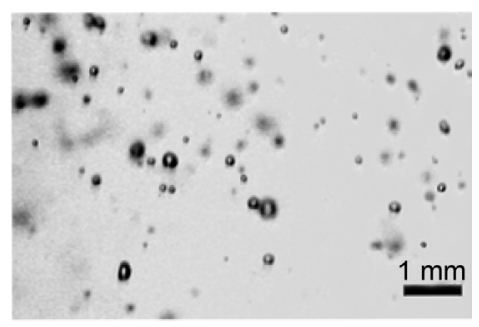

$[\Delta \mathrm{P}=2.0 \mathrm{~atm}]$

Figure 6. Droplet sizes and shapes at each pressure difference of the nozzle.

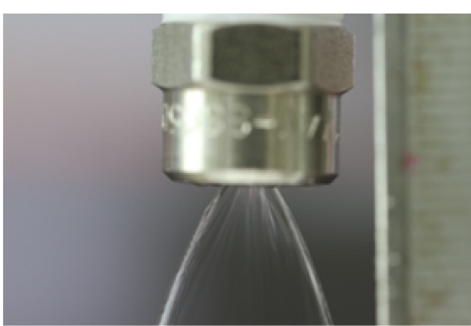

$[20 \mathrm{~mm}]$

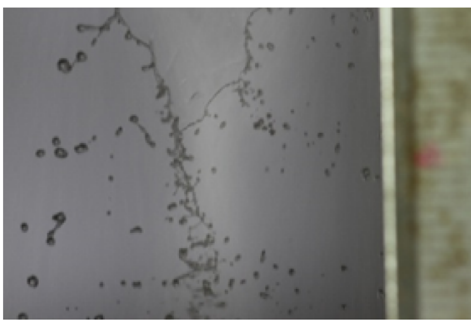

[60 mm]

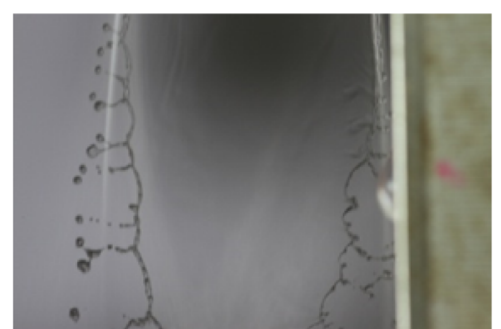

$[40 \mathrm{~mm}]$

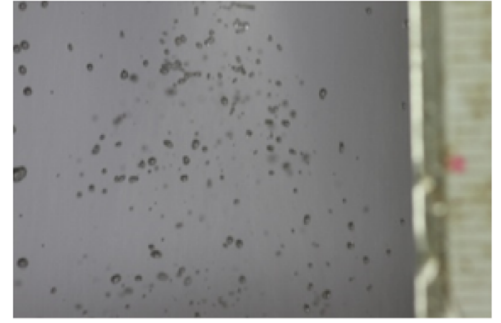

[80 mm]

Figure 7. Process of droplets formation at each SOD. 


\subsection{Experiment Results}

The experiments for the multiple degradations of FAC and LDIE were performed for the carbon steel of A106 B and the low alloy steel of A335 P22. Table 1 shows the properties of each material, wherein the $\mathrm{Cr}$ content of A335 P22 is nearly 6 times more than that of A106 B, but the yield strength of A335 P22 is approximately 70 percent of the A106 B.

For these two materials, the experiment was performed under the following conditions.

- $\mathrm{pH}: 4,4.5$, and 5 ,

- Velocities: 80, 100, and $120 \mathrm{~m} / \mathrm{s}$,

- Droplet sizes: 400 and $600 \mu \mathrm{m}$.

Figure 8 shows the state of the specimens before and after the experiment of the low-alloy steel (A335 P22) and the carbon steel (A106 B). After the experiments, the magnetite was formed on the surface of each specimen. In this figure, the surface of the specimen A106 B is much darker than the surface of the specimen A335 P22, which means that the formed magnetite on the surface of the A106 B was more than that of the surface of the A335 P22 in the same time. Figure 9 shows SEM images of each surface by time evolution under the conditions at $\mathrm{pH} 4$, the droplets velocity of $120 \mathrm{~m} / \mathrm{s}$ and the droplets diameter of 600 $\mu \mathrm{m}$. As a result, A106 B was damaged faster than A335 P22 in the beginning of the experiment, but it was hard to identify which specimens were more damaged after 100 hours.

Figure 10 shows the mass loss rate of two materials by the impact velocity of droplets. The total experiment time was 96 hours. As the impact velocity and the elapsed time were increased, so increased the cumulative mass loss rate of both materials. In the initial time of the experiment, the mass loss rate of A106 B was

Table 1. Properties for A106 B and A335 P22 materials.

\begin{tabular}{ccccccccccc}
\hline Materials & $\mathrm{C}$ & $\mathrm{Si}$ & $\mathrm{Mn}$ & $\mathrm{P}$ & $\mathrm{S}$ & $\mathrm{Cu}$ & $\mathrm{Ni}$ & $\mathrm{Cr}$ & $\mathrm{Mo}$ & $\sigma_{y}(\mathrm{MPa})$ \\
\hline A106 Gr.B & 0.28 & 0.1 & 1.16 & 0.03 & 0.03 & 0.04 & 0.40 & 0.40 & 0.15 & 288 \\
A335 P22 & 0.15 & 0.5 & 0.6 & 0.025 & 0.025 & - & - & 2.6 & 1.13 & 210 \\
\hline
\end{tabular}

[A106 B]

[A335 P22]

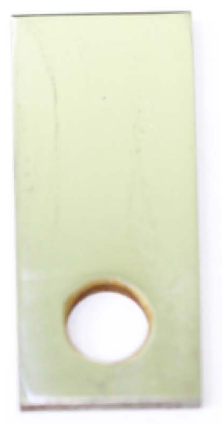

Before

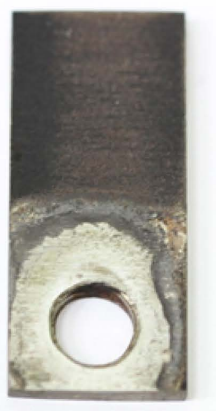

After

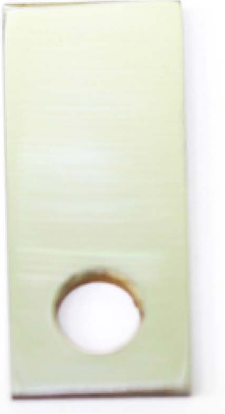

Before

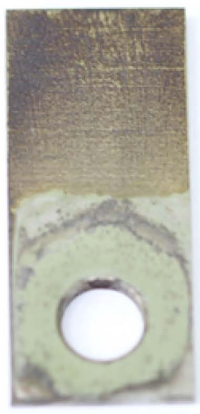

After

Figure 8. State of the specimens before and after 24 hours of experiment. 


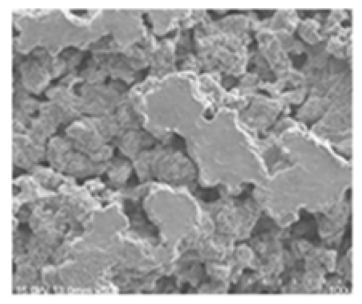

$24 \mathrm{hr}$ (surface, $\times 500$ )

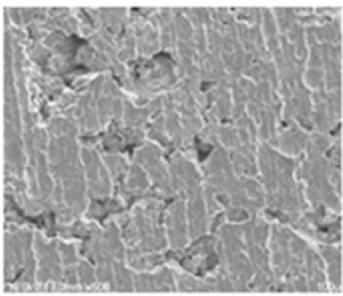

$24 \mathrm{hr}$ (surface, $\times 500$ )

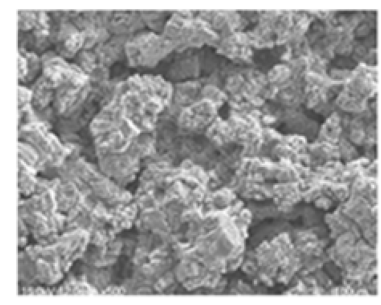

$55 \mathrm{hr}$ (surface, $\times 500$ )

[A106 B]

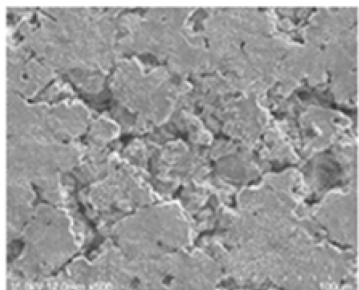

$55 \mathrm{hr}$ (surface, $\times 500)$

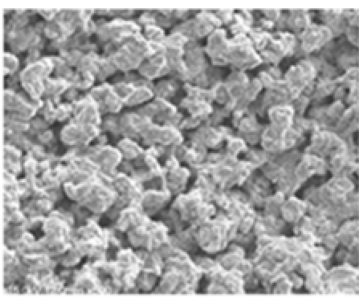

$100 \mathrm{hr}$ (surface, $\times 500$ )

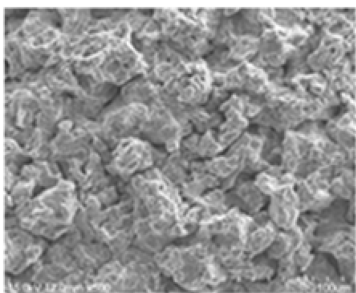

$100 \mathrm{hr}$ (surface, $\times 500)$

[A335 P22]

Figure 9. SEM images by time evolution.

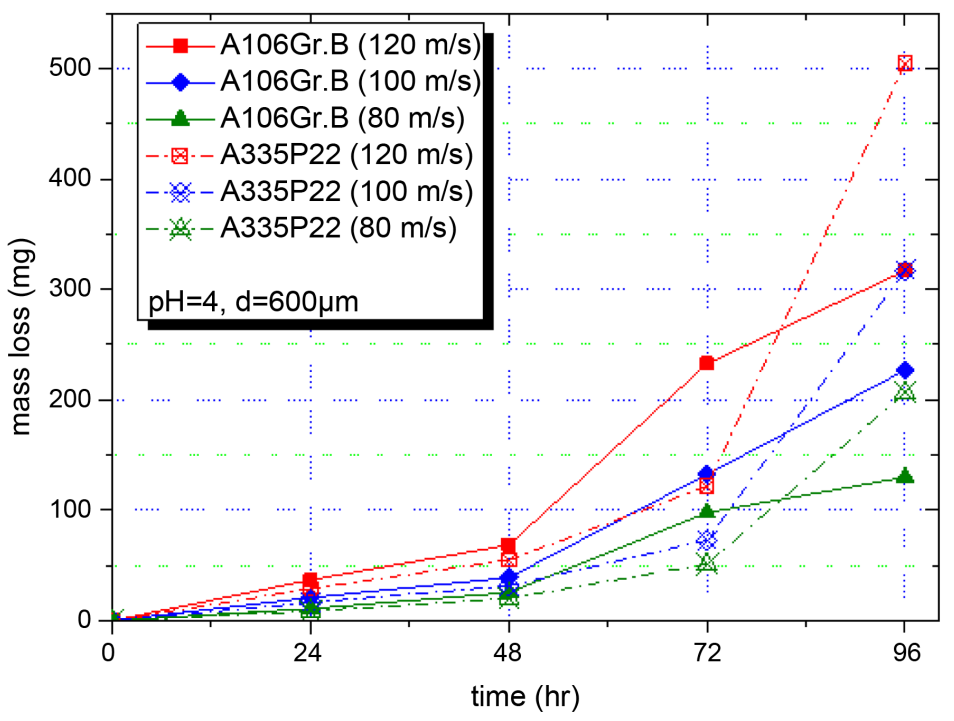

Figure 10. Cumulative mass loss rate of two materials by the impact velocity of droplets.

higher than A335 P22, but the mass loss rate of A335 P22 was higher than the A106 B after about 80 hours.

Figure 11 and Figure 12 show the mass loss rate of two materials by the $\mathrm{pH}$ and the droplets size, in which the mass loss rate of both materials was increased by decrease in the $\mathrm{pH}$ and increase in the droplets size. Thus, if the impact frequency per unit time is same, the mass loss rate of both materials will be increased by the increase in the droplets size.

The common phenomena in the Figures 9-11 are that the mass loss rate of A106 B was higher than the A335 P22 in the initial time of the experiments, but the mass loss rate of A335 P22 was higher than the A106 B after about 80 hours. 


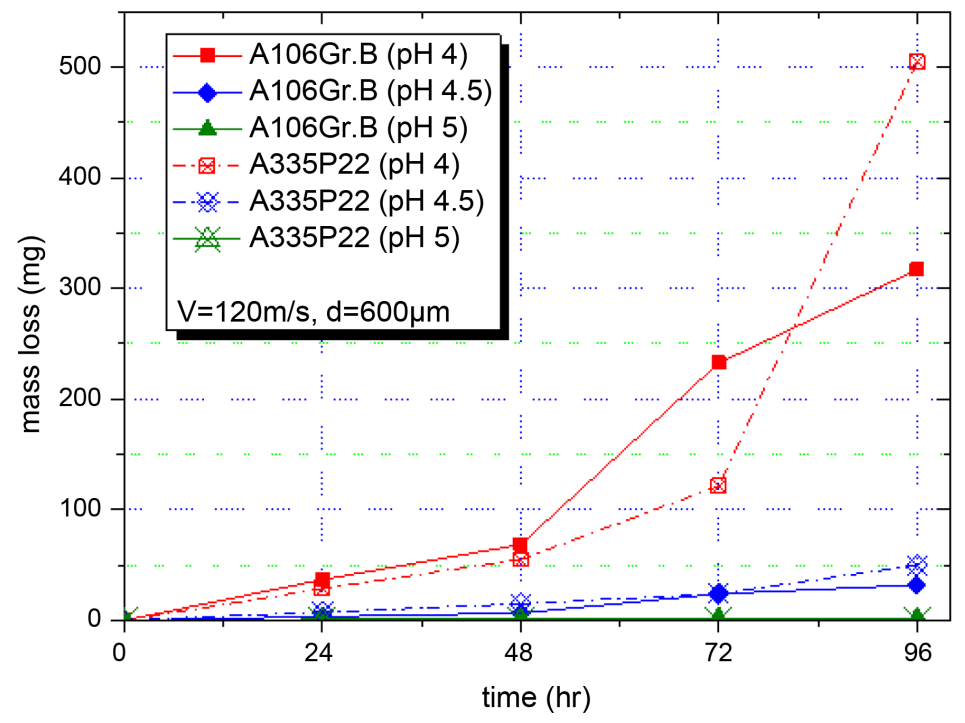

Figure 11. Cumulative mass loss rate of two materials by the $\mathrm{pH}$.

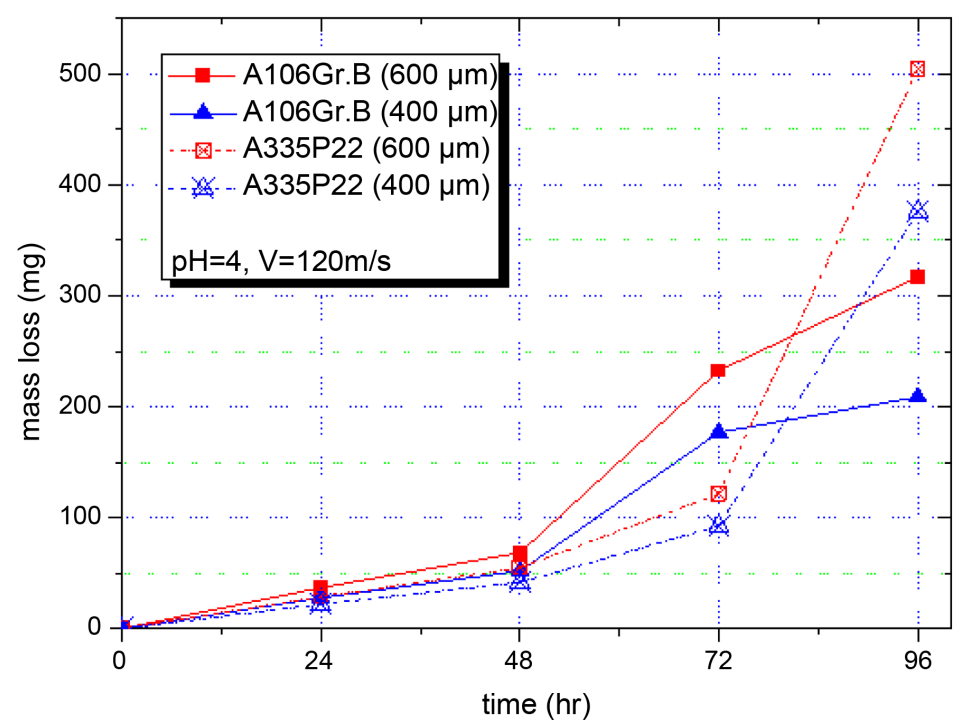

Figure 12. Cumulative mass loss rate of two materials by the size of droplets.

\section{Theoretical Prediction Model}

A small amount of sulfur ingredients are included in the carbon steel piping generally used in power plants. The sulfur effects on the brittleness of the material. Therefore, it is removed as much as possible in the manufacturing process of the pipe and the remaining sulfur is stabilized by manganese. However, the alabandite $(\mathrm{MnS})$ generated in this process can be vulnerable points to the pitting corrosion in a corrosive circumstance. As the surface roughness is increased in some degree by the repetition of occurrence and growth of the pitting corrosion, so displays a tendency to increase the erosion effect by physical collision of liquid droplets.

Figure 13 illustrates the process of material damage. Step 1 to 3 is the initiation stage, and the primary degradation mechanism is corrosion. The formation 
of MnS pits and the pit growth occurred in this stage. From the time (tc) when all the initial surface material is removed, the erosion caused by droplets impact is embossed as a major degradation mechanism. Of course, the corrosion continuously takes place. This step is the stable loss stage.

\subsection{Initiation Stage}

The Sulfur Print method [10] was applied to confirm the distribution of alabandite $(\mathrm{MnS})$ on the material surface. When comparing the sulfur printing results (large picture) with the experimental results in the condition of $\mathrm{pH} 5$ at the same magnification, it can be identified that the damaged locations, sizes and shapes are similar as shown in the Figure 14.

In other words, the stage before reaching the point tc means that the formation and growth of pitting corrosion are progressed at the locations of MnS, and the initial surface is damaged with the corroded points as its center.

Figure 15 shows the relationship between the normalized mass loss rate and the kinetic energy in the initiation stage. In the legend of the figure, the numbers

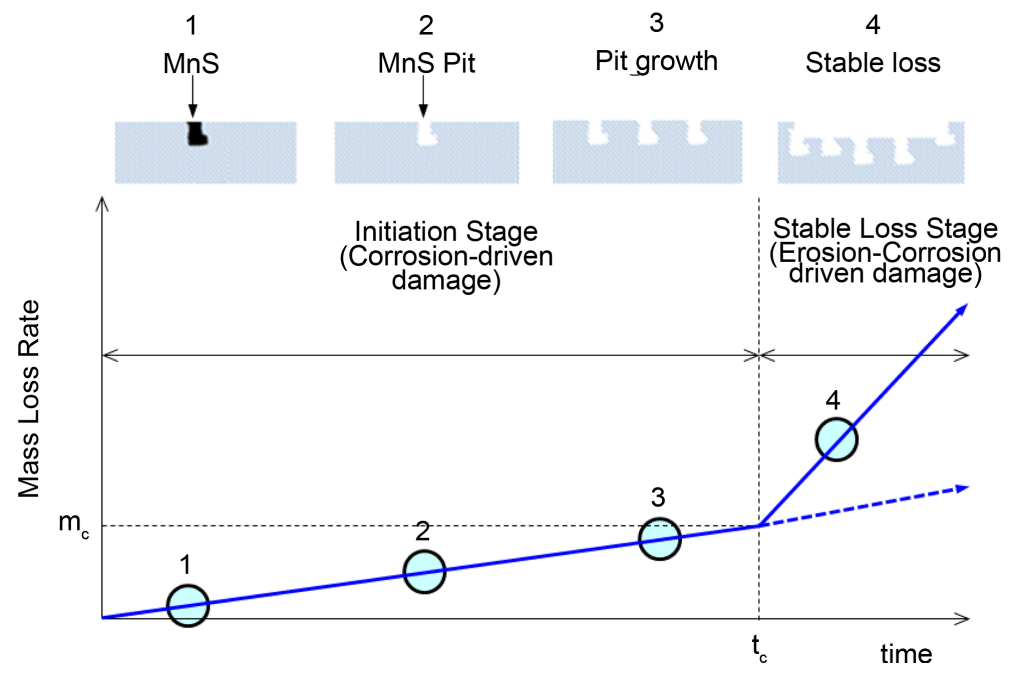

Figure 13. Process of material damage.
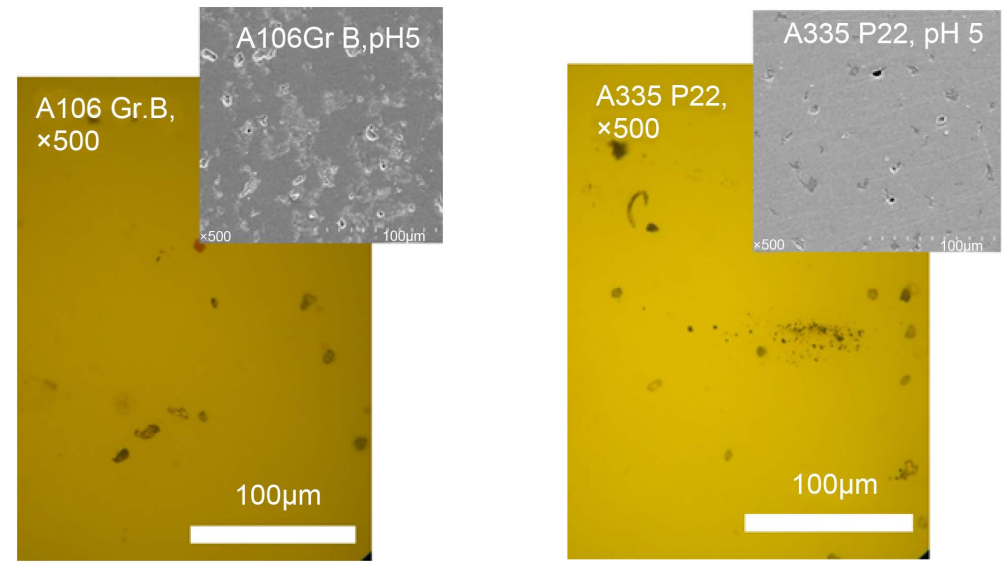

Figure 14. Sulfer distribution confirmed by the sulfer printing and the experimental results. 
mean $\mathrm{pH}$, droplets velocity, and droplets size in order. As a result, the mass loss rate of materials was found to be proportional to $\left(m V^{2}\right)^{1 / 5}$ in the initiation stage.

\subsection{Stable Loss Stage}

After the point $t_{c}$ the pitting corrosion is initiated again on the damaged surface, and the damage by physical collision of droplets occurred in the fragile parts structurally protuberated to the direction of thickness. As shown in Figure 16, the oxide layer on the surface is very thin to be about $1 \mu \mathrm{m}$ and in irregular shape. It is estimated that the oxide layer was damaged by the collision of droplets.

Figure 17 shows the relationship between the normalized mass loss rate after the point $t_{c}$ and the kinetic energy. This mass loss rate is a value obtained by

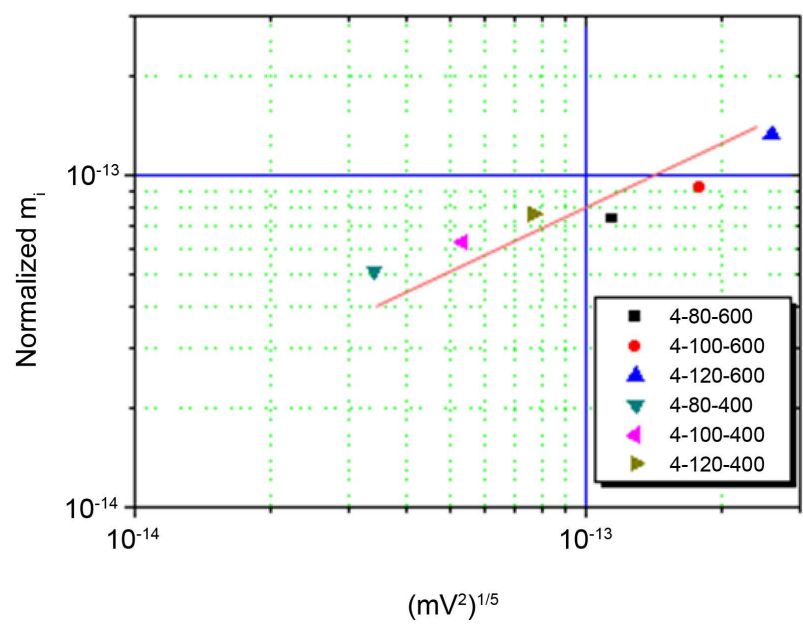

Figure 15. Relationship between the normalized mass loss rate and the kinetic energy in the initiation stage.
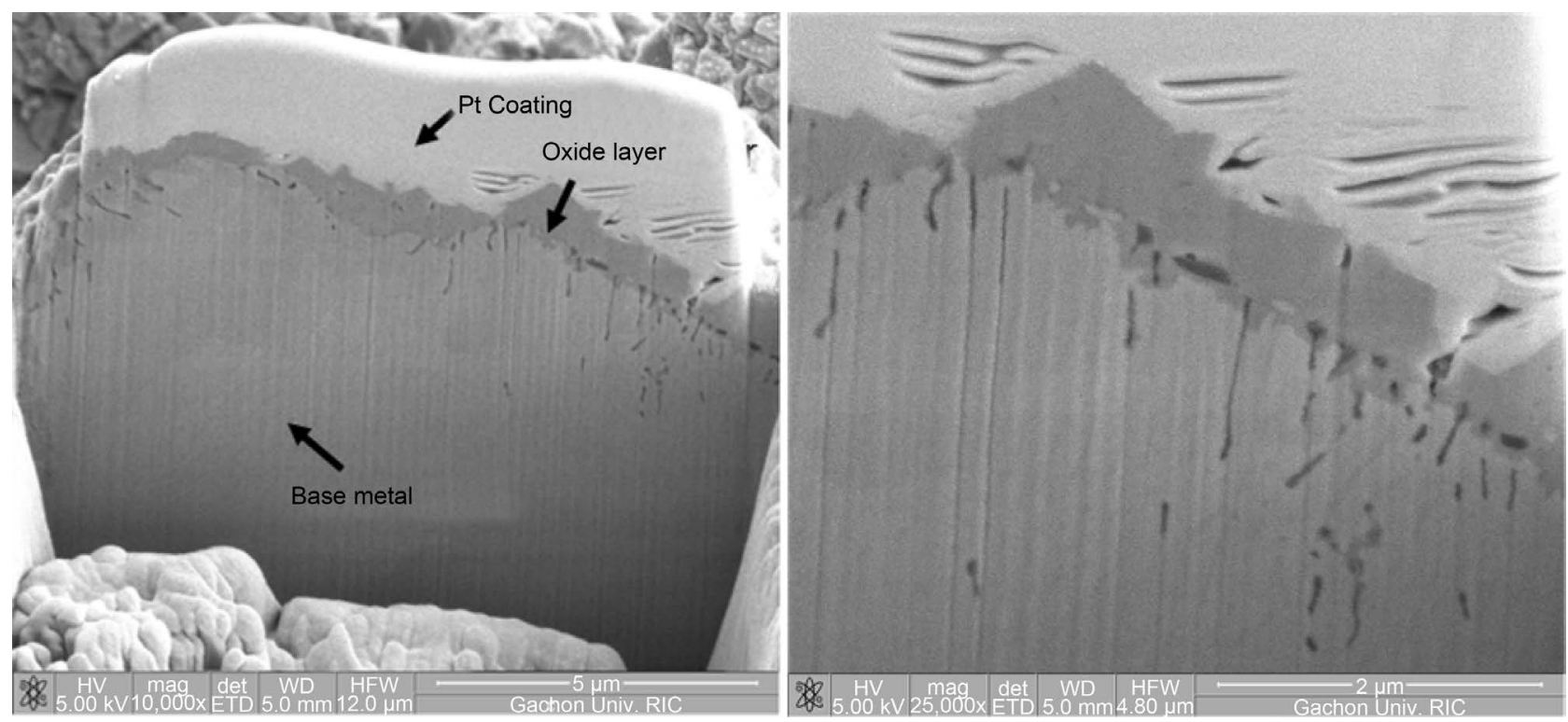

Figure 16. Cross section of A106 B. 


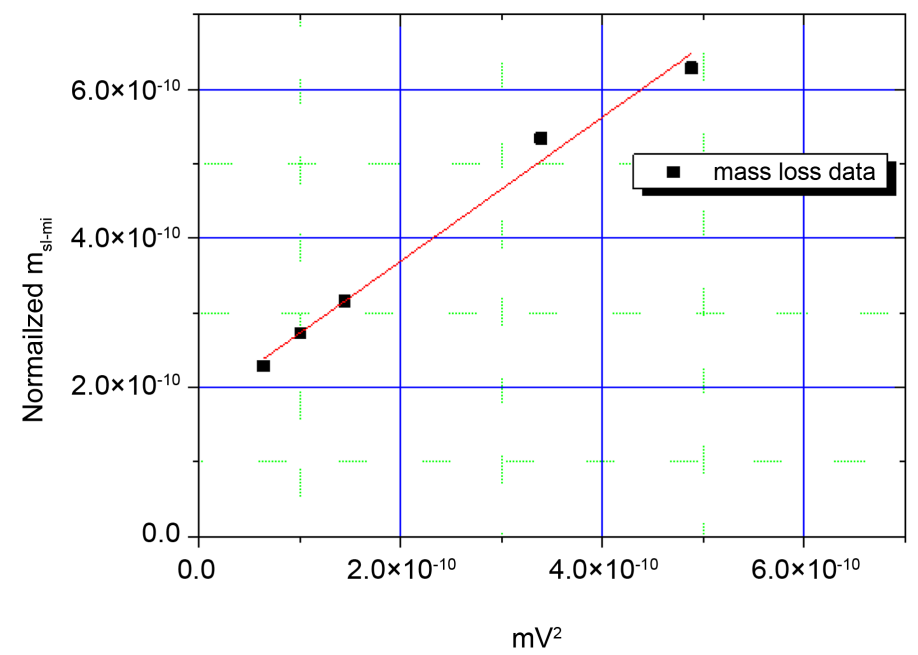

Figure 17. Relationship between the normalized mass loss rate and the kinetic energy (stable loss).

subtracting the loss rate in the initiation stage from the mass loss rate after the point $t_{c}$. As a result, the mass loss rate of materials was found to be proportional to $\left(m V^{2}\right)$ in the stable loss stage.

From these results, it was confirmed that the mass loss rate in the initiation stage is related to corrosion, and the mass loss rate in the stable loss stage is related to erosion. Equation (1) is the formula for the mass loss rate in the initiation stage, and Equation (2) is the formula described as the sum of the mass loss rate in the initiation and the stable loss stages.

$$
\begin{gathered}
\dot{m}_{i}=C_{0} \cdot\left(m_{d} \cdot V_{d}^{2}\right)^{\alpha} \cdot N_{d} \cdot S_{m} \cdot f(A C), \\
\dot{m}_{S L}=C_{1} \cdot m_{d} \cdot V_{d}^{2} \cdot N_{d} \cdot f(H v) \cdot f(\theta)+\dot{m}_{i}
\end{gathered}
$$

where, $\dot{m}_{i}$ : Mass loss rate in the initiation stage, $\mathrm{g} / \mathrm{cm}^{2} \cdot \mathrm{hr}$.

$\dot{m}_{S L}$ : Mass loss rate in the stable loss stage, $\mathrm{g} / \mathrm{cm}^{2} \cdot \mathrm{hr}$.

$C_{0}, C_{1}$ : Experimental constant $\left(C_{0}=1.15 \times 10^{-11}, C_{1}=1.0 \times 10^{-12}\right)$.

$\alpha$ : Experimental constant (0.2).

$m_{d}$ : Mass of a droplet, g.

$V_{d}$ : Velocity of droplets, g.

$N_{d}$ : Number of droplets.

$S_{m}$ : Solubility of magnetite, $\mathrm{g} / \mathrm{m}^{3}$.

$f(T)$ : Temperature correction factor.

$f(A C)$ : Alloy content correction factor $(\mathrm{Cr}, \mathrm{Mo}, \mathrm{Cu})$.

$f(\mathrm{Hv})$ : Vickers hardness correction factor.

$f(\theta)$ : Collision angle correction factor.

\section{Conclusions}

It is recently found that the wall thinning in the secondary side piping carrying two-phase flow is caused by not only FAC but also LDIE. It would be hard to believe that only LDIE degradation takes place. Grains are removed from the grain boundary on the surface of the materials by the repeated impact of liquid drop- 
lets, causing a sharp edge in the portion damaged by LDIE to appear. However, the carbon steel piping carrying two-phase flow in nuclear power plants damaged by LDIE has shown a special feature in the way that magnetite on the surface of the pipe wall is formed and the sharp edges at the grain boundaries cannot be identified. Also, because the water film is formed on the surface of the inside pipe wall, the liquid droplets cannot collide with the wall directly. Accordingly, it is more reasonable to assume that the degradations of FAC and LDIE occur at the same time.

In this study, an experimental facility equipped with droplet impingement and water treatment equipment was constructed to develop prediction models for multiple degradations caused by FAC and LDIE occurring in carbon steel piping. In the initial stage of the experiment, the mass loss rate of A106 B was greater than that of A335 P22, but after a critical period of time, the mass loss rate of A335 P22 was greater than that of A106 B.

It is attributable to the fact that the chrome content in A335 P22 is more than that in A106 B, so the magnetite formation was relatively small in the A335 P22. The mass loss rate is associated with the magnetite formed on the surface of the pipes and the yield strength of the materials. The magnetite formed on the surface of the pipes can alleviate the mass loss. Generally, the damaged carbon steel piping in nuclear power plants is replaced with low alloy steel. But, when selecting the pipe material, it should be considered as to whether the pipe will be used in the two-phase fluid system.

\section{References}

[1] Hwang, K.M. and Lee, D.Y. (2012) A Numerical Analysis Study to Identify the Leak Cause of Feedwater Vent Pipe in CANDU Plant. 24th Nuclear Simulation Symposium, Ottawa, 14-16 October 2012.

[2] Hwang, K.M., Lee, C.G., Bhang, K.J. and Yim, Y.S. (2011) A Study on the Design of a Pipe Affected by Liquid Droplet Impingement Erosion. Journal of Mechanical Science and Technology, B, 35, 1097-1103.

[3] Keck, R.G. and Griffith, P. (1987) Prediction and Mitigation of Erosive-Corrosive Wear in Secondary Piping Systems of Nuclear Power Plants. Massachusetts Institute of Technology, NUREG/CR-5007, 1-15.

[4] Heymann, F.J. (1969) High-Speed Impact between a Liquid Drop and a Solid Surface. Journal of Applied Physics, 40, 5113-5122. https://doi.org/10.1063/1.1657361

[5] Li, R., Ninokata, H. and Mori, M. (2011) Parametric Investigation on the Effect Factors for Liquid Droplet Impingement Erosion. Proceedings of ASME-JSMEKSME Joint Conference, Hamamatsu, 24-29 July 2011, AJK2011-03034. https://doi.org/10.1115/ajk2011-03034

[6] Morita, R. and Uchiyama, Y. (2012) Development of a Wall Thinning Rate Model for Liquid Droplet Impingement Erosion. Proceedings of ASME-JSME-KSME Joint Conference, Toronto, 15-19 July 2012, PVP2012-78443.

[7] Heymann, F.J. (1992) Liquid Impingement Erosion. ASM Handbook, 18, 221-232.

[8] Field, J.E., Dear, J.P. and Ogren J.E. (1989) The Effects of Target Compliance on Liquid Drop Impact. Journal of Applied Physics, 65, 533-540.

https://doi.org/10.1063/1.343136 
[9] ASTM G32-09 (1982) Standard Test Method for Liquid Impingement Erosion Using Rotating Apparatus.

[10] ASTM E1180-08 (2008) Standard Practice for Preparing Sulfur Prints for MacroStructural Evaluation.

Submit or recommend next manuscript to SCIRP and we will provide best service for you:

Accepting pre-submission inquiries through Email, Facebook, LinkedIn, Twitter, etc. A wide selection of journals (inclusive of 9 subjects, more than 200 journals)

Providing 24-hour high-quality service

User-friendly online submission system

Fair and swift peer-review system

Efficient typesetting and proofreading procedure

Display of the result of downloads and visits, as well as the number of cited articles

Maximum dissemination of your research work

Submit your manuscript at: http://papersubmission.scirp.org/

Or contactwjnst@scirp.org 